\title{
CAPÍTULO 52: COMPOSIÇÃO CENTESIMAL, ATIVIDADE ANTIOXIDANTE E ANTIMICROBIANA DE UMA PLANTA ALIMENTICIA NÃO CONVENCIONAL (PANC) DO GÊEERO Amaranthus
}

\author{
Karine Angélica Dalla Costa ${ }^{1}$; Mariane Ferenz ${ }^{2}$; Jean Carlos Budke ${ }^{3}$ Silvani Verruck $^{4}$; Sheila Mello da \\ Silveira ${ }^{5}$
}

\begin{abstract}
Resumo
Plantas alimentícias não convencionais são chamadas de "daninhas", "inços", "pragas", "invasoras" ou "espontâneas". Muitos estudos revelaram que essas plantas possuem teores de proteínas, vitaminas e outros nutrientes em quantidades mais elevadas que as plantas comumente utilizadas na alimentação. O objetivo deste estudo foi avaliar Amaranthus blitum L., popularmente conhecido como caruru, quanto à composição nutricional, propriedades antioxidantes e antimicrobianas. A espécie foi caracterizada quanto ao conteúdo de umidade, lipídios, proteínas, fibras e cinzas. Extratos aquosos e hidroalcoólicos de Amaranthus blitum L. foram obtidos para a realização dos testes de atividade antioxidante (radical ABTS) e antimicrobiana (difusão em ágar e microdiluição). A partir dos resultados, verificou-se ausência de atividade antimicrobiana frente às espécies de bactérias testadas e baixa a moderada atividade antioxidante. Amaranthus blitum L. apresentou 83,12 \% de umidade, 1,70\% de lipídios, 6,22 \% de proteína, $1,97 \%$ de fibras e 2,64 \% de cinzas, sendo estes valores superiores aos normalmente encontrados em hortaliças convencionais. Por este motivo, Amaranthus blitum L. surge como uma alternativa barata e de fácil acesso para melhorar a qualidade da dieta da população brasileira, visto que é uma espécie vegetal encontrada abundantemente na natureza e ainda é pouco explorada para este fim.
\end{abstract}

Palavras-Chave: Amaranthus blitum L., caruru, composição nutricional, alimento.

\begin{abstract}
Unconventional edible plants are called "weed", "plague" "invasive" or "spontaneous". Many studies showed that these plants have levels of protein, vitamins and other nutrients in higher quantities than in the plants commonly used as food. The objective of this study was to evaluate Amaranthus blitum L., popularly known as pigweed, in its nutritional composition, antioxidant and antimicrobial properties. The species was characterized by the moisture content, lipid, protein, fiber and ashes. Aqueous and hydroalcoholic extracts of Amaranthus blitum L. were obtained for the performance of antioxidant (ABTS radical) and antimicrobial (agar diffusion and microdilution) tests. The results showed the absence of antimicrobial activity from Amaranthus blitum L. extracts compared to the bacteria species tested and low antioxidant activity. Amaranthus blitum L. showed $83.12 \%$ moisture, $1.70 \%$ lipids, $6.22 \%$ protein, $1.97 \%$ fiber and $2.64 \%$ ash, these values being higher than those typically found in conventional vegetables. For this reason, Amaranthus blitum L. may be an alternative for human consumption, since it is a species found abundantly in nature and it is not explored by consumers.
\end{abstract}

Keywords: Amaranthus blitum L., pigweed, nutritional composition, food.

\footnotetext{
${ }^{1}$ Engenharia de alimentos, Universidade Regional Integrada do Alto Uruguai e das Missões karinedallacosta@hotmail.com

${ }^{2}$ Engenharia de alimentos, Instituto Federal Catarinense, mariane.ferenz@ @otmail.com

${ }^{3}$ Prof. Dr., Universidade Regional Integrada do Alto Uruguai e das Missões, jean@uricer.edu.br

${ }^{4}$ Prof ${ }^{a}$ Dra., Universidade Federal de Santa Catarina, silvani.verruck@ufsc.br

${ }^{5}$ Prof $^{a}$ Dra., Instituto Federal Catarinense, sheila.silveira@ifc.edu.br
} 


\section{Introdução}

A alimentação adequada é um direito social fundamental do ser humano, inerente à sua dignidade e indispensável, devendo o poder público garantir a segurança alimentar e nutricional da população (BRASIL, 2010; BRASIL, 2014). No mundo há cerca de 815 milhões de pessoas que estão passando fome, segundo relatório divulgado pela ONU (2018). No entanto a solução para esta insegurança alimentar não é apenas aumentar a produção de alimentos, mas também reduzir os impactos ambientais gerados. Uma alternativa para diminuir este número alarmante, poderia ser a valorização daquelas espécies vegetais que estão próximas das residências e propriedades, que a população pouco conhece e nem imagina que possam ser utilizadas como alimento (POLESI et al., 2017).

As plantas alimentícias não convencionais (PANCs) são as chamadas de matos, daninhas ou inços que medram entre as plantas cultivadas. Muitas das PANCs eram amplamente utilizadas, mas estão em desuso pela maior parte da população por diferentes fatores, tais como a competição no mercado com as hortaliças convencionais, mudanças de hábito de alimentação, baixa disponibilidade no mercado e não comercialização. Por isso, em determinadas regiões são consideradas não convencionais (FLECK et al., 2015; KINUPP, 2007).

Além da ampliação da oferta e variedade de itens alimentícios disponíveis à população, as PANCs ainda se inserem como potenciais de incremento nas dietas alimentares, complementando a ingestão de calorias, de micro e macro nutrientes (KINUPP, 2014). Rapport e Drausal (2001) estimam que existem 27 mil espécies com potencial alimentício no mundo. Kinupp (2007), em levantamento botânico na área metropolitana de Porto Alegre - RS identificou 311 espécies com potencial alimentício, dentre 1.500 espécies coletadas. Muitas das espécies de PANCs, quando comparadas com suas espécies aparentadas, incluem muito mais nutrientes, vitaminas, antioxidantes, compostos fenólicos, carotenóides, quantidades consideráveis de minerais como potássio, magnésio, manganês, vitamina $\mathrm{C}$ e próvitamina A, lipídeos, proteínas, fibras em altas quantidades, o que é enfatizado por diferentes autores (KINUPP, 2007; KINUPP e BARROS, 2008; OLIVEIRA et al., 2013; BIONDO et al., 2013; KINUPP e LORENZI, 2014; FLECK et al., 2015; POLESI, et al., 2017; FLECK, SANT'ANNA e BIONDO, 2017; ZEM et al., 2017).

Além disso, consumidores estão buscando cada vez mais por produtos de origem natural principalmente os provenientes de espécies vegetais, em função de alguns 
antioxidantes e antimicrobianos sintéticos serem alvos de questionamentos quanto à inocuidade, demostrando a possibilidade de desencadear alguma complicação à saúde do consumidor.

O presente estudo teve como intuito ampliar o conhecimento sobre uma PANC da região do oeste Catarinense, a fim obter informações que possam contribuir para a valorização da cultura local, aumento do consumo de PANC, bem como conservação dos recursos vegetais alimentícios. No mundo existem cerca de 60 espécies pertencentes ao gênero Amaranthus, família Amaranthaceae. São conhecidas popularmente por Caruru, Caruru-bravo, Bredo, Caruru-rasteiro, Caruru-roxo, Caruru-branco, Caruru-verde, entre outros (TEUTONICO e KNORR, 1985).

Dado o exposto, pesquisas direcionadas à caracterização nutricional e avaliação do potencial antioxidante e antimicrobiano de espécies da família Amaranthaceae podem vir a contribuir para a dieta alimentar bem como ampliar e diversificar a alimentação. $\mathrm{O}$ objetivo do presente trabalho foi avaliar uma planta alimentícia não convencional: Amaranthus blitum L. quanto à composição nutricional, e investigar a presença de propriedades antioxidantes e antimicrobianas em extratos preparados a partir desta espécie vegetal.

\section{Material e Métodos}

\section{Material vegetal}

A espécie vegetal Amaranthus blitum L., popularmente conhecida como Caruru, foi coletada na cidade de Concórdia - SC, Brasil (27²18'46" Sul, 51 $59^{\circ} 16^{\prime \prime}$ Oeste) em julho de 2015. A identificação botânica foi efetuada pelo Dr. J. C. Budke (URI, RS, Brasil). A exsicata das espécies vegetal foi depositada no Herbário Padre Balduíno Rambo (HPBR) do Departamento de Ciências Biológicas (URI) e identificadas pelo número de registro 11.912. 
Figura 1. Exsicata de Amaranthus blitum L.

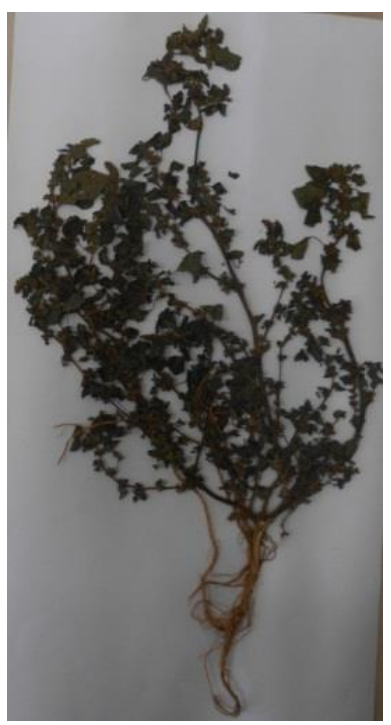

Fonte: Própria (2015).

As partes da planta (folha jovem, folha madura e caule) foram lavadas e submetidas à secagem em estufa (Solab SL - 102) com circulação de ar a $40{ }^{\circ} \mathrm{C}$ por $48 \mathrm{~h}$. Posteriormente, foram submetidas à trituração manual e por fim pesadas.

\section{Obtenção dos extratos}

\section{Obtenção do extrato aquoso}

A infusão da matéria seca foi realizada de acordo com Ferris e Zheng (1999), com adaptações. Misturou-se $20 \mathrm{~g}$ da planta seca com $200 \mathrm{~mL}$ de água destilada aquecida a $80{ }^{\circ} \mathrm{C}$, para obtenção do extrato bruto a $10 \%$. A mistura foi mantida em repouso por 10 min e posteriormente filtrada em papel filtro para obtenção do extrato límpido. Foram realizadas três repetições da preparação do extrato aquoso.

\section{Obtenção do extrato hidroalcoólico}

A obtenção do extrato hidroalcoólico foi realizada por maceração. Em erlenmeyers foram introduzidos 20 gramas de planta seca e adicionados $200 \mathrm{~mL}$ de solução de etanol:água 80:20 (v/v) como solvente. Os extratos foram mantidos em temperatura ambiente, ao abrigo da luz por $72 \mathrm{~h}$, e foram agitados a cada $24 \mathrm{~h}$. Foram realizadas três repetições da preparação do extrato hidroalcoólico.

Posteriormente os extratos foram filtrados e concentrados em evaporador rotativo (Biothec, modelo BT 351) acoplado a banho ultratermostático (Solab modelo SL 152) até a eliminação do solvente e obtenção do extrato bruto etanólico (adaptado de CAI, SUN e CORKE, 2003). 
COSTA, K. A. D; FERENZ, M; BUDKE, J. C; VERRUCK, S; SILVEIRA, S. M.

Todos os extratos foram armazenados a $4{ }^{\circ} \mathrm{C}$ em recipiente de vidro hermeticamente fechado e ao abrigo da luz.

\section{Determinação da composição centesimal}

A determinação da umidade foi realizada por secagem em estufa (Edutec, modelo EEQ9020D-2, Brasil) a $105^{\circ} \mathrm{C}$ até peso constante (IAL, 2005).

O teor de proteína foi determinado pelo método de Kjeldahl através da conversão de nitrogênio total em proteína de acordo com a metodologia preconizada pelo Instituto Adolfo Lutz (IAL, 2008). Baseou-se em três etapas: digestão, destilação e titulação. A digestão das amostras foi realizada em um digestor, a destilação em destilador (Kjeltec, modelo 1026) e a titulação foi realizada com solução padrão de ácido clorídrico $0,1 \mathrm{~mol} / \mathrm{L}$ até a viragem do indicador. Utilizou-se o fator de 6,25 para conversão em proteína bruta.

O conteúdo de lipídios foi determinado pela extração utilizando-se éter etílico como solvente, sob refluxo durante $8 \mathrm{~h}$ em aparelho Soxhlet (Nova ética) acoplado ao banho ultratermostático (Solab modelo SL 152) conforme o método estabelecido pelo Instituto Adolfo Lutz (IAL, 2005).

A determinação do resíduo mineral fixo (cinzas) foi realizado por incineração em mufla (Jung), a $600^{\circ} \mathrm{C}$ por $6 \mathrm{~h}$ (IAL, 2005).

O teor da fibra bruta foi realizado conforme o método Ba 6a-05 (AOAC, 2009). As digestões ácidas e alcalinas foram realizadas no determinador de fibra (Tecnal modelo TE - 149) acoplado ao banho ultratermostático (Solab, modelo SL 152).

\section{Avaliação da atividade antimicrobiana}

\section{Método de difusão em ágar}

A detecção de atividade antimicrobiana dos extratos sobre as bactérias testadas foi realizada conforme o método de difusão em disco com base no documento M2-A8 do CLSI (CLSI, 2009a), com adaptações conforme Silveira (2012). Primeiramente, realizouse a ativação das bactérias: estriou-se colônias para ágar sangue e incubou-se a $35^{\circ} \mathrm{C}$ por 12-18 h. Transferiu-se destas placas de 3 a 5 colônias isoladas para caldo triptose de soja (TSB), incubado a $35^{\circ} \mathrm{C}$ por 2 a $6 \mathrm{~h}$, a fim de obter culturas em fase de crescimento ativo.

O inóculo foi preparado a partir da cultura ativa de cada espécie bacteriana, diluída em solução salina $0,9 \%$ a uma concentração de aproximadamente $10^{8} \mathrm{UFC} \mathrm{mL}^{-1}$, comparável à solução padrão de McFarland 0,5, verificada espectrofotometricamente a $625 \mathrm{~nm}$. A suspensão foi então diluída a aproximadamente $10^{7} \mathrm{UFC} \mathrm{mL} \mathrm{m}^{-1}$, em solução salina, e esta solução foi utilizada para inocular placas de petri contendo ágar Mueller- 
COSTA, K. A. D; FERENZ, M; BUDKE, J. C; VERRUCK, S; SILVEIRA, S. M.

Hinton, utilizando-se swab estéril.

Foram testadas seis espécies de bactérias, sendo três espécies Gram-positivas e três Gram-negativas, respectivamente: Bacillus cereus ATCC 11778, Staphylococcus aureus ATCC 25923 e Listeria monocytogenes ATCC 19117; Escherichia coli ATCC 25922, Pseudomonas aeruginosa ATCC 27853 e Yersinia enterocolitica ATCC 9610.

Os extratos hidroalcoólicos foram diluídos a concentração de $100 \mathrm{mg} \mathrm{mL}^{-1} \mathrm{com}$ dimetilsulfóxido (DMSO), enquanto os extratos aquosos foram testados sem diluição. Discos de papel filtro estéreis (9 $\mathrm{mm}$ de diâmetro e $250 \mathrm{~g} \mathrm{~m}^{-2}$ ) foram impregnados com $25 \mu \mathrm{L}$ de extrato e depositados sobre as placas inoculadas, as quais foram incubadas por $24 \mathrm{~h}$ a $36{ }^{\circ} \mathrm{C}$. Discos comerciais de ampicilina $\left(10 \mu \mathrm{g}\right.$ disco $\left.^{-1}\right)$ e cloranfenicol $(30 \mu \mathrm{g}$ disco $^{-1}$ ) foram utilizados como controles positivos e discos impregnados com DMSO (25 $\mu \mathrm{L})$ como controle negativo.

O diâmetro da zona de inibição foi medido, em milímetros, e a inibição foi classificada como forte, moderada ou fraca conforme Carovic-Stanko et al. (2010). O ensaio foi realizado em triplicata e o valor apresentado como a média ( \pm desvio padrão). Concentração mínima inibitória (CMI)

Os extratos foram avaliados quanto à Concentração Mínima Inibitória (CMI) através do método de microdiluição com base no documento M7-A6 da CLSI (CLSI, 2009b) e com adaptações conforme Silveira (2012).

Os extratos aquosos foram testados em uma faixa de 100 a $0,75 \mathrm{mg} / \mathrm{mL}$ e os extratos hidroalcoólicos em uma faixa de 10 a $0,075 \mathrm{mg} / \mathrm{mL}$.

Foram mantidos controles de esterilidade (caldo Mueller-Hinton adicionado de DMSO e sem adição de inóculo) e controles de crescimento (caldo Mueller-Hinton adicionado de DMSO e inóculo). A incubação das placas foi realizada a $36{ }^{\circ} \mathrm{C}$ por $18-24$ h e o crescimento microbiano foi detectado visualmente e confirmado pela adição de solução aquosa de cloreto de trifeniltetrazólio (TTC) a $0,5 \%(\mathrm{~m} / \mathrm{v})$. As análises foram realizadas em triplicata e a CMI foi definida como a menor concentração de cada extrato que inibiu totalmente o crescimento microbiano.

\section{Atividade antioxidante}

A avaliação da atividade antioxidante foi realizada através do ensaio de capacidade de sequestro do radical 2,2'azinobis-3-etilbenzotiazolina-6-ácido sulfônico $\left(\mathrm{ABTS}^{\bullet+}\right)$ conforme Re et al. (1998) com algumas adaptações. Inicialmente, preparou a solução de $\mathrm{ABTS}^{\cdot+}$ através da reação do $\mathrm{ABTS}$ em solução aquosa a $7 \mathrm{mM} / \mathrm{L}$ e persulfato de potássio $\left(\mathrm{K}_{2} \mathrm{~S}_{2} \mathrm{O}_{8}\right)$ a 2,45 mM/L. Misturou-se quantidades iguais de ambas as soluções, 
agitou-se e então esta mistura foi armazenada por $16 \mathrm{~h}$ em temperatura ambiente em ausência da luz. Transcorrido o tempo, antes de ser usada, esta solução foi diluída com etanol até obter uma solução com leitura de absorbância de aproximadamente 0,700 a 734 nm. Os extratos foram diluídos até que ocorresse uma inibição entre 20-80\% em relação ao branco. Posteriormente, $3 \mathrm{~mL}$ da solução previamente preparada de $\mathrm{ABTS}^{\bullet+}$ foi misturada com $30 \mu \mathrm{L}$ da solução do extrato devidamente diluída, a mistura foi agitada e permaneceu em repouso por 6 minutos em ausência de luz e temperatura ambiente. Passado este tempo a absorbância foi imediatamente medida em espectrofotômetro (Biospectro modelo SP-220) a $734 \mathrm{~nm}$.

A análise foi realizada em triplicata para todas as amostras e o valor apresentado como a média ( \pm desvio padrão). Para a elaboração da curva padrão, usou-se o antioxidante sintético Trolox (Ácido 6-hidroxi-2,5,7,8-tetrametil-cromano-2-carboxílico) na faixa de concentração de 0,5-2,0 mM/L, em etanol. Os resultados foram expressos como mmol equivalente de Trolox por grama de extrato ( $\mu$ mol TEAC. $\mathrm{g}^{-1}$ extrato).

\section{Resultados e Discussão}

\section{Composição centesimal}

A Tabela 1 apresenta os resultados da caracterização nutricional da planta Amaranthus blitum L.

Tabela 1. Composição centesimal de Amaranthus blitum L.

\begin{tabular}{lc}
\hline Análises & Conteúdo $(\%)$ \\
\hline Umidade a $105^{\circ} \mathrm{C}$ & $83,12 \pm 2,23$ \\
Lipídeos & $1,70 \pm 1,020$ \\
Proteína bruta** & $6,22 \pm 0,26$ \\
Fibra bruta & $1,97 \pm 0,64$ \\
Cinzas & $2,64 \pm 0,07$
\end{tabular}

Resultados apresentados como média \pm desvio padrão, $n=3$.

$* * \mathrm{~N} \times 6,25$

Fonte: Própria (2015).

O conteúdo de fibras de $A$. blitum L. encontra-se inferior quando comparado a outras espécies do gênero Amaranthus. Estudos desenvolvidos por Connor et al. (1980) e Uso e Okorie (1983) apontaram teores de fibras entre 3,2-5,8\% para Amaranthus edulis e $8,1 \%$ para Amaranthus hybridus. Porém, A. blitum L. destacou-se frente a certas 
hortaliças, como agrião $(1,5 \%)$, serralha $(0,4 \%)$ e a folhosa mais consumida, a alface $(0,7 \%)$, apresentando teor de fibra superior (FURLANI, FURLANI e BATAGLIA, 1978). É interessante referir que a fibra dietética é importante, pois mantém o funcionamento normal do trato gastrointestinal. Ainda, sua presença nos alimentos induz à saciedade, no momento das refeições (FENNEMA, DAMODARAM e PARKIN, 2010).

Na Tabela 2 pode-se observar o conteúdo proteico de algumas espécies de Amaranthus e de algumas hortaliças convencionais. Desta forma, em relação ao conteúdo proteico de A. blitum L., nota-se que este se encontra inferior em comparação a outras plantas do mesmo gênero (A. edulis e A. hybridus), mas quando comparado com os teores de algumas hortaliças convencionais, como repolho, couve, alface, cenoura, brócolis e acelga a planta avaliada deste estudo destacou-se por apresentar teores superiores $(6,22 \%)$ de proteínas. De modo geral, os vegetais são considerados fontes proteicas pobres (MELO e FARIA, 2014).

Tabela 2. Conteúdo proteico de algumas espécies do gênero Amaranthus e de hortaliças convencionais.

\begin{tabular}{lcc}
\hline Espécie & Conteúdo $(\%)$ & Referência \\
\hline A. Edulis & $15,8-16,5$ & Amaya-Farfan, Marcílio e Spehar (2005) \\
A. hybridus & $14,0-17,2$ & Melo, Faria (2014) \\
Repolho & 1,58 & Melo, Faria (2014) \\
Couve & 1,38 & Melo, Faria (2014) \\
Alface & 0,89 & Melo, Faria (2014) \\
Cenoura & 0,73 & Saggin (2017) \\
Brócolis & 2,11 & Saggin (2017) \\
Brócolis & 2,02 & Maggiorini e Sassano (2013) \\
Acelga & 2,28 & Pereira et al. (2016) \\
\hline
\end{tabular}

Fonte: Própria (2015).

O conteúdo de lipídios e cinzas obtido para A. blitum L. foi de 1,70 e 2,64\%, respectivamente, teores estes inferiores aos obtidos para outras plantas do mesmo gênero.

Amaya-Farfan, Marcílio e Spehar (2005) obtiveram em seus estudos teor de lipídios entre 6,9 e 8,1\% para A. edulis, e entre 14,0 e 17,2 para o A. hybridus. Araújo, Menezes e Tomazini (2009), em seu estudo com plantas alimentícias convencionais, verificou teores de lipídios para agrião em torno de $0,60 \%$, indicando teor superior em $A$. blitum L. (1,70\%). 
Amaya-Farfan, Marcílio e Spehar (2005) também avaliaram teores de cinzas para A. edulis e A. hybridus, que apresentaram teores de 4,4 e 4,2\%, respectivamente. Comparando o conteúdo de cinzas com vegetais convencionais como o agrião $(1,04 \%)$, brócolis $(0,68 \%)$, cenoura $(0,82 \%)$, couve-flor $(1,02 \%)$, acelga $(0,52 \%)$ e couve $(1,61 \%)$ observou-se teor superior para A. blitum L. (2,64\%) (ARAÚJO, MENEZES e TOMAZINI, 2009; SAGGIN, 2017; PEREIRA et al., 2016). Esse conteúdo superior de cinzas em $A$. blitum L. em relação à planta convencional destaca-se, pois o conteúdo de cinzas é um indicativo do conteúdo de minerais, o que implica em seu valor nutricional. O teor de cinzas em alimentos refere-se ao resíduo inorgânico, ou resíduo mineral fixo (sódio, potássio, magnésio, cálcio, ferro, fósforo, cobre, cloreto, alumínio, zinco, manganês e outros compostos minerais) remanescente da queima da matéria orgânica em mufla a altas temperaturas (500-600 $\left.{ }^{\circ} \mathrm{C}\right)$ (ZAMBIAZI, 2010). Para estudos futuros sugere-se a determinação do perfil de minerais contidos nesta planta.

Diferenças quanto à composição centesimal entre as espécies do gênero Amaranthus podem ser explicadas pela variação do clima, do solo, estação do ano, características intrínsecas da própria espécie, diversidade genética, idade da planta no momento da colheita, entre outros (ASCHERI, CARVALHO e SPEHAR, 2004).

Avaliando o teor de umidade pode-se observar que as folhas e o caule da planta pesquisada contém teor elevado de umidade, o que é um indicador de vegetais frescos, assim como da sua elevada perecibilidade. Esse teor encontrado é semelhante ao obtido por outros autores em plantas comestíveis não convencionais. Oliveira (2013) encontrou para Pereskia aculeata (Ora-pro-nobis) e Xanthosoma sagittifolium (Taioba) valores de 86,99 e $82,96 \%$, respectivamente.

Sabe-se que vivemos num mundo onde existem muitos problemas tanto de desnutrição das populações menos favorecidas quanto de desperdícios das matériasprimas e alimentos de origem vegetal. Em virtude disso, avaliando os resultados obtidos, apresenta-se A. blitum L. como uma alternativa para dieta da população. Em comparação com certas hortaliças convencionais consumidas no dia-a-dia, A. blitum L. encontrou-se com teores nutricionais superiores, indicando potencialidade que ainda não é explorada por parte dos consumidores.

\section{Atividade antimicrobiana}

Não foi detectada atividade antimicrobiana através dos métodos difusão em disco e concentração mínima inibitória (CMI) de ambos os extratos testados de A. blitum L., 
frente as espécies bacterianas testadas. Na Tabela 3 podem ser observadas as zonas de inibição dos antibióticos sintéticos cloranfenicol e ampicilina, utilizados como controles positivos neste ensaio.

Tabela 3. Atividade antimicrobiana dos antibióticos sintéticos ampicilina e cloranfenicol detectado no ensaio de difusão em disco (mm).

\begin{tabular}{lcc}
\hline Bactérias Gram-positivas & Ampicilina & Cloranfenicol \\
Bacillus cereus ATCC 11778 & $14,5 \pm 0,6$ & $28 \pm 0,0$ \\
Staphylococcus aureus ATCC 25923 & $22 \pm 0,6$ & $28 \pm 0,0$ \\
Listeria monocytogenes ATCC 19117 & $28,5 \pm 0,6$ & $25,5 \pm 1,1$ \\
Bactérias Gram-negativas & & \\
Escherichia coli ATCC 25922 & $22 \pm 0,0$ & $22 \pm 1,0$ \\
Yersinia enterocolitica ATCC 9610 & $24,5 \pm 0,0$ & $33 \pm 0,6$ \\
Pseudomonas aeruginosa ATCC 27853 & $0,0 \pm 0,0$ & $0,0 \pm 0,0$
\end{tabular}

Resultados apresentados como a média \pm desvio padrão, $\mathrm{n}=3$. Graus de inibição: 10 -13,9 mm: fraca; 1418 mm: moderada; >18 mm: forte; nd: não detectado.

Fonte: Própria (2015).

Natalli e seus colaboradores (2011) reportaram atividade antimicrobiana de um extrato etanólico de A. viridis frente a bactérias patogênicas de interesse no setor alimentício. O experimento indicou atividade contra Escherichia coli, Staphylococcus aureus e Bacillus cereus, com CMIs iguais a 7,9, 62,5 e 31,2 $\mu \mathrm{g} / \mathrm{mL}$, respectivamente. Através da concentração mínima bactericida (CMB), os autores verificaram que aquele extrato apresentou atividade bactericida significativa em relação às três espécies testadas.

Nduche, Iwuoha e Igbokwe (2016) determinaram as propriedades antimicrobianas de extratos aquosos de A. spinosus, A. hybridus para quatro espécies bacterianas patogênicas: S. aureus, E. coli, Salmonella Typhimurium e Candida albicans. A concentração mínima inibitória (CMI) mostrou que os extratos possuem propriedades antimicrobianas em concentrações que variam de 12,50 a $200 \mathrm{mg} / \mathrm{ml}$. Contudo, todos os extratos em teste tiveram atividade menor que a dos antibióticos padrões.

Cruz (2010), em seu estudo, avaliou a atividade antimicrobiana através do método de difusão em disco de extratos hidroalcóolicos e aquoso de Amaranthus asplundii contra Streptococcus mutans, Klebsiella pneumoniae e o fungo Candida albicans. Os resultados apontaram baixa atividade através do método empregado. 


\section{Atividade antioxidante}

A atividade antioxidante dos extratos aquosos e hidroalcoólicos da planta $A$. blitum L. está apresentada na Tabela 4. Foram realizadas três repetições para cada amostra de extrato.

Tabela 4. Atividade antioxidante dos extratos aquosos e hidroalcoólicos de A. blitum L. avaliada pelo método ABTS.

\begin{tabular}{lc}
\hline Amostra & ABTS $^{\mathbf{a}}(\boldsymbol{\mu m o l ~ T E A C / g})^{\mathbf{b}}$ \\
\hline Aquoso 1 & $35,5 \pm 2,0$ \\
Aquoso 2 & $31,7 \pm 4,2$ \\
Aquoso 3 & $39,2 \pm 2,9$ \\
Hidroalcoólico 1 & $234,3 \pm 16,0$ \\
Hidroalcoólico 2 & $259,7 \pm 7,3$ \\
Hidroalcoólico 3 & $218,9 \pm 14,8$
\end{tabular}

Resultados apresentados como média \pm desvio padrão, $\mathrm{n}=3$.

aABTS: radical 2,2'-azinobis-(3-etilbenzotiazolina-6-ácido sulfônico); ' $\mu$ mol TEAC/g: capacidade antioxidante equivalente ao Trolox por grama de extrato.

Fonte: Própria (2015).

Analisando o resultado obtido nota-se que o extrato hidroalcoólico exerceu maior atividade que os extratos aquosos, indicando que a extração etanólica, em termos de compostos fenólicos foi muito mais eficiente. Os compostos fenólicos são considerados antioxidantes primários presentes nas espécies vegetais (SHYLAJA e PETER, 2004).

Esta diferença entre os extratos também pode estar envolvida com o modo de preparação dos mesmos, visto que o extrato hidroalcoólico foi submetido à maceração por $72 \mathrm{~h}$ e foi concentrado em rotavapor, enquanto o extrato aquoso foi obtido pelo método de infusão e não passou pela etapa de concentração, a fim de simular uma futura utilização em nível doméstico, através da preparação de um chá por infusão, prática rotineira de grande parte da população.

Vários estudos foram realizados acerca das atividades antioxidantes de espécies do gênero Amaranthus. Entretanto, diversos trabalhos utilizaram o método de captura dos radicais DPPH, tornando a comparação dos resultados com este estudo difícil. Outro fator que contribui para a dificuldade de comparação entre diferentes estudos são as modificações introduzidas nas metodologias, tais como os volumes adicionados das soluções de extrato e/ou de radical livre (SILVEIRA, 2012). 
Souza (2013) reportou elevada atividade antioxidante $(13439,45 \mu \mathrm{M}$ TEAC/g) para um extrato hidroalcoólico (etanol) obtido a partir das folhas de guabiroba, sendo quase cinco vezes maior que o menor valor obtido naquele estudo, exibido pelas folhas de acerola (3040,85 $\mu \mathrm{M}$ TEAC/g). Estes valores são muito superiores aos observados no presente estudo, podendo-se considerar como baixa a atividade antioxidante apresentada pelos extratos da espécie A. blitum L.

Estudos realizados por Simão e seus colaboradores (2012) demonstraram atividade antioxidante moderada para as folhas de marmelinho tanto para o extrato aquoso $\left(728,80 \mu \mathrm{mol} \mathrm{TEAC} \mathrm{g}{ }^{-1}\right)$ quanto para o etanólico $\left(731,06 \mu\right.$ mol TEAC $\left.\mathrm{g}^{-1}\right)$. Para as demais plantas pesquisadas no estudo (babosa, calunga e carqueja) as atividades antioxidantes foram relativamente baixas, na faixa de 1,74 a $33,78 \mu$ mol TEAC $\mathrm{g}^{-1}$.

Extratos hidroalcoólicos das folhas de Parapiptadenia rigida (angico vermelho), estudados por Silveira (2012) apresentaram relevante atividade antioxidante: $1965 \mu \mathrm{mol}$ TEAC $\mathrm{g}^{-1}$, sendo este teor muito superior aos extratos deste estudo. A espécie vegetal estudada por Silveira (2012) que obteve maior semelhança com A. blitum L. (faixa de 202,9 a 267,0 $\mu \mathrm{mol}$ TEAC $\left.\mathrm{g}^{-1}\right)$ foi a Persea americana Mill $\left(233 \mu \mathrm{mol}\right.$ TEAC $\left.\mathrm{g}^{-1}\right)$, popularmente conhecida como o abacate.

Bergamaschi (2010) avaliou a atividade antioxidante de resíduos de vegetais usualmente consumidos pela população. Película de amendoim, casca de maracujá, folha/talho de nabo, resíduo de alcachofra, casca de abóbora, folha/talo de cenoura, folha/talo de rabanete, talo de beterraba, talo de brócolis e couve foram estudados quanto à sua capacidade de sequestro do radical ABTS em extrato etanólico e aquoso. Os resultados indicaram maior atividade para a película de amendoim, apresentando teores de 990,79 $\mu$ mol TEAC g ${ }^{-1}$ de resíduo vegetal para extrato hidroalcoólico e 262,12 $\mu$ mol TEAC $\mathrm{g}^{-1}$ de resíduo vegetal para extrato aquoso. A menor capacidade foi detectada para o resíduo de alcachofra $\left(3,40 \mu \mathrm{mol}\right.$ TEAC $\mathrm{g}^{-1}$ de resíduo vegetal para extrato hidroalcoólico, 3,19 $\mu$ mol TEAC g-1 de resíduo vegetal extrato aquoso, respectivamente).

No estudo de Saggin (2017) a atividade antioxidante foi avaliada para três alimentos orgânicos (brócolis, cenoura e couve-flor) em extrato de metanol: acetona, apresentando 120,$12 ; 65,75$ e 48,26 $\mu$ mol TEAC g ${ }^{-1}$, respectivamente.

Clemes, Beirith e Zeni (2015) avaliaram a capacidade antioxidante de seis espécies da mata atlântica, dentre elas uma espécie da família Amaranthaceae: Alternanthera dentada, que apresentou insignificante atividade antioxidante para extrato aquoso $\left(0,05 \mu \mathrm{mol}\right.$ TEAC $\left.\mathrm{g}^{-1}\right)$ e etanólico $\left(1,02 \mu \mathrm{mol} \mathrm{TEAC} \mathrm{g}^{-1}\right)$. 


\section{Conclusões}

Os extratos de Amaranthus blitum L. testados não apresentaram atividade antimicrobiana frente as espécies testadas e a atividade antioxidante observada pode ser considerada como baixa. Contudo, a espécie vegetal Amaranthus blitum L. exibiu propriedades nutricionais interessantes, com teores superiores de proteína, fibras e cinzas em comparação a diversas hortaliças convencionais. Por este motivo, a espécie Amaranthus blitum L. pode ser uma alternativa barata e de fácil acesso para melhorar a qualidade da dieta da população brasileira, visto que atualmente é um recurso genético com usos potenciais inexplorados. Além disso, é importante considerar que os consumidores têm apreciado a disponibilização de alimentos naturais e saudáveis, e que possam ainda trazer algum benefício à saúde. Esta planta pode ser introduzida às refeições do consumidor como salada ou acompanhamento com outras hortaliças, entretanto faz-se necessário analisar futuramente sua aceitabilidade sob o ponto de vista sensorial.

\section{Referências}

AMAYA-FARFAN, J.; MARCÍLIO, R.; SPEHAR, C. R. Deveria o Brasil investir em novos grãos para a sua alimentação? A proposta do amaranto (Amaranthus sp.). Segurança alimentar e nutricional. Ensaios e Ciência: Ciências Biológicas, Agrárias e da Saúde, v. 12, n. 1, p. 47-56, 2005.

AOAC. Crude Fiber Analysis in Feeds by Filter Bag Technique Ba 6a-05. 2009.

ARAUUJO, E. M.; MENEZES, H. C.; TOMAZINI, J. M. Fibras solúveis e insolúveis de verduras, tubérculos e canela para uso em nutrição clínica. Ciência e Tecnologia de Alimentos, p. 401-406, 2009.

ASCHERI, J. L. R.; CARVALHO, C. W. P.; SPEHAR, C. R. A extrusão do amaranto no desenvolvimento de produtos: caracterização físico-química. EMBRAPA Agroindústria de Alimentos, 31 p. 2004.

BERGAMASCHI, K. B. Capacidade antioxidante e composição química de resíduos vegetais visando seu aproveitamento. Dissertação de mestrado. Universidade de São Paulo. Piracicaba, SP, 2010. 97 p.

BIONDO, E.; CEMIN, P.; SIMIONI, C.; KOLCHINSKI, E.; SANT'ANNA, V., ZAMBIASI, I. Caracterização citogenética e ecológica de populações de mamãozinho- 
COSTA, K. A. D; FERENZ, M; BUDKE, J. C; VERRUCK, S; SILVEIRA, S. M.

do-mato (Vasconcellea quercifolia A.St.Hill - Caricaceae) uma planta alimentícia nãoconvencional pouco explorada. Cadernos de Agroecologia, v. 8, n. 2, p. 1-4, 2013.

BRASIL. Ministério da Agricultura, Pecuária e Abastecimento, MAPA. Hortaliças não convencionais (tradicionais). Secretaria de Desenvolvimento Agropecuário e Cooperativismo. Brasília: MAPA/ACS, 52p. 2010.

BRASIL. Ministério da Agricultura, Pecuária e Abastecimento. Manual de Hortaliças Não-Convencionais. Brasília, DF: MAPA/ACS, 92p. 2010.

BRASIL. Ministério da Saúde. Guia alimentar para a população brasileira: promovendo a alimentação saudável. Brasília: Ministério da Saúde, 2014.

BURT, S. Essential oils: their antibacterial properties and potential applications in foods - a review. International Journal of Food Microbiology, v. 94, p. 223-253, 2004.

CAI, Y.; SUN, M.; CORKE, H. Antioxidant activity of betalains from plants of the Amaranthaceae. Journal of Agricultural and Food Chemistry, v. 51, p. 2288-2294, 2003.

CAROVIC-STANKO, K.; ORLIC, S. POLITEO, O.; STRIKIC, F.; KOLAK, I.; MILOS, M.; SATOVIC, Z. Composition and antibacterial activities of essential oils of seven Ocimum taxa. Food Chemistry, v. 119, p. 196-201, 2010.

CLEMES, S. M.; BEIRITH, A.; ZENI, A. L. B. Avaliação de polifenóis e capacidade antioxidante de seis espécies da Mata Atlântica. Scientia Plena. v. 11, n. 5, 2015.

CLSI (Clinical and Laboratory Standards Institute). Methods for dilution antimicrobial susceptibility tests for bacteria that grow aerobically; approved standard. 8.ed. 940 West Valley Road, Suite 1400, Wayne, Pennsylvania 19087-1898 USA, 2009b. (CLSI document M7-A6 [ISBN 1-56238-486-4]).

CLSI (Clinical and Laboratory Standards Institute). Performance standards for antimicrobial disk susceptibility tests: approved standard. 8.ed. 940 West Valley Road, Suite 1400, Wayne, Pennsylvania 19087-1898 USA, 2009a. (CLSI document M2A8 [ISBN 1-56238-485-6]).

CRUZ, C. D. G. Evaluación de la actividad antibacteriana y Antimicótica de los extractos de Myrciantes hallii (arrayán), Amaranthus asplundii (ataco), Peperomia 
peltigera (pataku Yuyo), especies reportadas en peguche - imbabura, Sobre Streptococcus mutans, Klebsiella pneumoniae, Candida albicans Causantes de enfermedades bucofaríngeas. Monografia (Engenharia em biotecnologia). Departamento de ciências, 2010. 167 p.

FENNEMA, O. R.; DAMODARAM, S.; PARKIN, K. L. Química de Alimentos de Fennema, 4 ed. Artmed, 2010, 400p.

FERRIS, H.; ZHENG, L. Plant Sources of Chinese Herbal Remedies: Effects on Pratylenchus vulnus and Meloidogyne javanica. Journal of Nematology, California, v. 31, n. 3, p. 241-263, 1999.

FLECK, M.; SANT'ANNA, V.; BIONDO, E. Centesimal and mineral analysis of native wild strawberries from southern of Brazil. In: 16th Euro-Global Summit on Food and Beverages, 2017, Amsterdã. Anais 16th Euro-Global Summit on Food and Beverages, v. 8. p. 101-101, 2017.

FLECK, M.; SILVA, M. R. S.; BIONDO, E.; KOLCHINSKI, E. M.; SANT’ANNA, V. Plantas alimentícias não convencionais ocorrentes no Vale do Taquari e suas principais utilizações. In: $5^{\circ}$ Simpósio de segurança alimentar e nutricional: alimentação e saúde, 2015, Bento Gonçalves. Anais. 2015. Disponível em: http://www.ufrgs.br/sbctarseventos/gerenciador/painel/trabalhosversaofinal/SAM273.pd f. Acesso em: 17 de junho 2018.

FURLANI, A.C.M.; FURLANI, P.R.; BATAGLIA, O.C. Composição mineral de diversas hortaliças. Bragantia, Campinas, v.37, p.33-44, 1978.

IAL (INSTITUTO ADOLFO LUTZ). Métodos físico-químicos para análise de alimentos. 4 ed. São Paulo: IAL, 2005. 1018 p.

IAL (INSTITUTO ADOLFO LUTZ). Métodos físico-químicos para análise de alimentos. 4 ed. São Paulo: IAL, 2008.

ICMSF - International Commission on Microbiological Specifications for Foods. Microorganisms in Foods, vol 5: Microbiological Specifications of Food Pathogens. Londres, Reino Unido: Kluwer Academic / Plenum Publishers. p. 20-180, 2003.

KINUPP, V. F. Riqueza de plantas alimentícias não-convencionais na região 
metropolitana de Porto Alegre. In: Plantas alimentícias não-convencionais da Região Metropolitana de Porto Alegre, RS. Tese - (Doutorado em Fitotecnia), Faculdade Agronomia, Universidade Federal do Rio Grande do Sul. Porto Alegre, 2007. 562 p.

KINUPP, V. F.; BARROS, I. B. I. de. Teores de proteína e minerais de espécies nativas, potenciais hortaliças e frutas. Ciência e Tecnologia de Alimentos. v. 28, n. 4, p. 846$857,2008$.

KINUPP, V.F.; LORENZI, H. Plantas Alimentícias Não-Convencionais (PANC) no Brasil: guia de identificação, aspectos nutricionais e receitas ilustradas. Nova Odessa: Ed. Plantarum, 768p. 2014.

MELO, C. M. T.; FARIA, J. V. Composition, phenolic compounds and antioxidant activity in conventional not edible part of six vegetables. Bioscience Journal, v. 30, p. 93-100, 2014.

NATAlli, V. D.; BARCElOS, R. M.; PINTO, A. P. A.; RESENDE, K. M.; BELINELO, V. J. Investigação fitoquímica e atividade antimicrobiana de Amaranthus viridis L. (AMARANTHACEAE). Enciclopédia Biosfera, Centro Científico Conhecer - Goiânia, v. 7, n. 12, 9 p. 2011.

NDUCHE, M.U.; IWUOHA, C. D.; IGBOKWE, A. U. Antibacterial Activity of Four Nigerian Medicinal Plants. Scholars Journal of Agriculture and Veterinary Sciences, v. 3, n. 3, p. 172-180, 2016.

OLIVEIRA, D. C. S.; WOBETO, C.; ZANUZO, M. R.; SEVERGNINI C. Composição mineral e teor de ácido ascórbico nas folhas de quatro espécies olerícolas nãoconvencionais. Horticultura Brasileira, v. 31, p. 472-475, 2013.

OLIVEIRA, S. R. de. Plantas Alimentícias não convencionais (PANCs) voltam a ganhar espaço na mesa dos brasileiros. Revista Letras da Terra, n. 36, p. 6-8, 2013.

ONU BR. Organização das nações unidas do Brasil. Disponível em: http://www.onu.org.br/index.php?s=fome $\& x=0 \& y=0$. Acesso em 6 de junho de 2018.

PEREIRA, E. M.; LEITE, D. D. F.; FIDELIS, V. R. L.; PORTO, R. M.; OLIVEIRA, M. I. V.; MAGAlHÃES, W. B. Caracterização físico-química de hortaliças tipo folha comercializadas no Brejo Paraibano. Agropecuária Técnica, v. 37, n. 1, p. 19-22, 2016. 
POLESI, R. G.; ROLIM, R.; ZANETTI, C.; SANT'ANNA, V.; BIONDO, E. Agrobiodiversidade e segurança alimentar no vale do taquari, RS: plantas alimentícias não convencionais e frutas nativas. Revista Cientifica Rural, v. 19, n. 2, 2017.

RAPOPORT, E. H.; DRAUSAL, B. S. Edible plants. In: S. LEVIN (Ed.). Encyclopedia of biodiversity. New York: Academic Press, p. 375-382, 2001.

RE, R.; PELLEGRINI, N.; PROTEGGENTE, N.; PANNALA, A.; YANG, M. EVANS, C. R. Antioxidant activity applying na improved ABTS radical cation decolorization assay. Free Radical Biology and Medicine, v. 26, p. 1231-1237, 1999.

SAGGIN, S. F. Avaliação físico-química de hortaliças orgânicas congeladas. Monografia (Nutrição). Universidade Regional do Noroeste do Estado do Rio Grande do Sul, RS, 2017. 26 p.

SILVEIRA, S. M. Avaliação da atividade antimicrobiana e antioxidante de extratos vegetais e óleos essenciais e aplicação do óleo essencial de louro (L. nobilis) como agente conservador natural em embutido cárneo frescal. Tese de doutorado. Universidade Federal de Santa Catarina. Florianópolis, SC, 2012. 215 p.

SIMÃO, A. A.; CORRÊA, A. D.; MARQUES, T. R.; RAMOS, V. O. ALVES, A.P. C. DUARTE, M. H. Atividade antioxidante de plantas medicinais. $\mathbf{5 2}^{\mathbf{0}}$ Congresso Brasileiro de Química. 2012.

SOUZA, W. de. Avaliação da atividade antioxidante e compostos fenólicos de extratos vegetais. Trabalho de conclusão de curso. Universidade Tecnológica Federal do Paraná, Campo Mourão, PR. 2013, p. 31.

TEUTONICO, R. A.; KNORR, D. Amaranth; composition, properties and applications of a rediscovered crop. Food Technology, v. 39, n. 4, p. 49-59, 1985.

ZAMBIAZI, R.C. Análise Físico Química de Alimentos. Pelotas: Editora Universitária, 202 p. 2010.

ZEM, L. M.; HELM, C. V.; ZUFFELLATO-RIBAS, K. C. Z.; KOEHLER, H. S. Centesimal and mineral anlysis of cupcakes base meal of leaves and stems of ora-pronobis (Pereskia aculeata). Revista Eletrônica Científica UERGS, v. 3, n. 2, p. 428-446, 2017.

Disponível

em: 
COSTA, K. A. D; FERENZ, M; BUDKE, J. C; VERRUCK, S; SILVEIRA, S. M.

https://ainfo.cnptia.embrapa.br/digital/bitstream/item/163084/1/2017-CrisH-RECCentesimal.pdf. Acesso em: 17 de junho de 2018. 